\title{
Dopaminergic Modulation of Prefrontal Cortical Input to Nucleus Accumbens Neurons In Vivo
}

\author{
Anne Marie Brady and Patricio 0’Donnell \\ Center for Neuropharmacology and Neuroscience, Albany Medical College, Albany, New York 12208
}

\begin{abstract}
Dopaminergic transmission in the nucleus accumbens has been proposed to modulate the effects of converging excitatory inputs from the cortex, hippocampus, and amygdala. Here, we used in vivo intracellular recording in anesthetized rats to examine the response of nucleus accumbens neurons to stimulation of the prefrontal cortex (PFC) and the ventral tegmental area (VTA). The EPSP elicited in accumbens neurons by PFC stimulation was attenuated by VTA train stimulation in a pattern mimicking dopamine cell burst firing. PFC-elicited EPSPs were smaller in amplitude and faster to decay after VTA stimulation. These changes could not be explained by membrane depolarization alone, because EPSPs evoked during the sustained depolarization after VTA stimulation were significantly smaller than EPSPs evoked during spontaneously occurring up states. Furthermore, no attenuation of PFC-elicited responses was observed during depolarization produced by positive current injection through the recording electrode. Administration of a $\mathrm{D}_{1}$ antagonist ( $\mathrm{SCH} 23390 ; 0.5 \mathrm{mg} / \mathrm{kg}$, i.p.) had no effect on the VTA reduction of PFC-elicited responses, whereas administration of a $\mathrm{D}_{2}$ antagonist (eticlopride; $0.5 \mathrm{mg} / \mathrm{kg}$, i.p.) reversed the reduction of PFC inputs when the analysis was limited to comparisons with spontaneous up states. These results suggest that the ability of PFC inputs to drive accumbens neurons is dampened by dopamine acting primarily at $\mathrm{D}_{2}$ receptors. Along with previous reports of dopaminergic attenuation of limbic afferents to the accumbens, these findings support the hypothesis that dopamine mediates the selection and integration of excitatory inputs and thus shapes information processing in accumbens output neurons.
\end{abstract}

Key words: dopamine; glutamate; nucleus accumbens; prefrontal cortex; ventral tegmental area; in vivo intracellular recording

\section{Introduction}

The nucleus accumbens receives excitatory inputs from diverse forebrain areas, including the prefrontal cortex (PFC), hippocampus, and amygdala (Pennartz et al., 1994; O’Donnell and Grace, 1995; Groenewegen et al., 1999). Ascending projections from the ventral tegmental area (VTA) provide both dopaminergic and GABAergic innervation of the accumbens (Sesack and Pickel, 1990; Van Bockstaele and Pickel, 1995). Both electrophysiological and electron-microscopic findings suggest that these inputs converge onto single accumbens neurons (O'Donnell and Grace, 1995; Finch, 1996; French and Totterdell, 2002). These findings suggest that the nucleus accumbens is well positioned to integrate a wide range of limbic and motor information (Mogenson et al., 1988; Meredith and Totterdell, 1999). Accordingly, the nucleus accumbens and its dopaminergic input have been implicated in various motivational, behavioral, and cognitive functions, including the regulation of motor activity (Dalia et al., 1998), response to salient or novel stimuli (Rebec et al., 1997; Horvitz, 2000), stress (Kalivas and Duffy, 1995), sensorimotor

Received Sept. 11, 2003; revised Nov. 25, 2003; accepted Dec. 1, 2003.

This work was supported by National Institutes of Health Grants MH60131 and DA14020 and a National Alliance for Research on Schizophrenia and Depression Independent Investigator Award to P.O'D., and National Research Service Award DA14821 to A.M.B. We thank Maureen 0'Keefe and Nicole Barnhardt for their assistance with histological processing, and Kuei-Yuan Tseng and Barbara Lewis for helpful comments on this manuscript.

Correspondence should be addressed to Dr. Anne Marie Brady, Albany Medical College, Mail Code-136, 47 New Scotland Avenue, Albany, NY 12208. E-mail: bradyam@mail.amc.edu.

DOl:10.1523/JNEUROSCI.4178-03.2004

Copyright $\odot 2004$ Society for Neuroscience $\quad$ 0270-6474/04/241040-10\$15.00/0 gating (Swerdlow et al., 2001), and instrumental conditioning (Salamone et al., 1999; Corbit et al., 2001). Dysfunctions in accumbens afferent and efferent pathways have been hypothesized to underlie the behavioral and cognitive impairments characteristic of schizophrenia (O'Donnell and Grace, 1998) and addiction (Hyman et al., 2001).

Despite the wealth of experimental data illustrating the importance of dopaminergic activity in the nucleus accumbens for behavioral processes, the effects of dopamine (DA) at the cellular level remain poorly understood. Activation of dopaminergic pathways or receptors has been shown to either increase (Gonon and Sundstrom, 1996) or decrease (DeFrance et al., 1985; White and Wang, 1986) firing activity in accumbens neurons. Although dopamine is typically found to depolarize accumbens neurons (Uchimura et al., 1986; Yim and Mogenson, 1988; O'Donnell and Grace, 1994, 1996; Goto and O'Donnell, 2001), these apparently excitatory effects are often accompanied by reduced excitability (O'Donnell and Grace, 1996) or a decrease in action potential firing (Yim and Mogenson, 1988; Goto and O'Donnell, 2001). There is also some evidence that dopamine may exert a tonic inhibition on accumbens neurons (Mulder et al., 1996).

An alternative conceptualization holds that dopamine does not have simple excitatory or inhibitory actions, but instead modulates the effects of other inputs to the nucleus accumbens (Mogenson et al., 1988; O'Donnell, 1999). Synaptic responses in accumbens neurons driven by stimulation of either the amygdala or the hippocampus are attenuated by stimulation of the VTA or 
local iontophoretic application of dopamine in vivo (Yang and Mogenson, 1984; DeFrance et al., 1985; Yim and Mogenson, 1988). Excitatory accumbens responses to PFC stimulation are also decreased by direct application of dopaminergic receptor agonists in vitro (Pennartz et al., 1992; O'Donnell and Grace, 1994; Harvey and Lacey, 1996; Nicola et al., 1996). However, the effects of dopamine and/or activation of the ascending dopaminergic fibers on PFC synaptic responses have not yet been investigated in vivo. These experiments were designed to examine interactions between dopamine and PFC inputs to the accumbens in vivo, with the hypothesis that stimulation of the VTA in a pattern resembling dopamine cell burst firing would dampen synaptic responses to PFC stimulation in nucleus accumbens neurons.

\section{Materials and Methods}

Subjects. Male adult Sprague Dawley rats were obtained from Taconic (Germantown, NY) $(n=20)$ or Charles River Laboratories (Wilmington, MA) $(n=44)$. All of the experiments were conducted in accordance with guidelines published in the United States Public Health Service Guide for the Use and Care of Animals, and all of the procedures were approved by the Albany Medical College Institutional Animal Care and Use Committee.

Electrophysiological recordings. Animals (300-450 gm) were initially anesthetized with chloral hydrate $(400 \mathrm{mg} / \mathrm{kg}$, i.p. $)$ and placed in a stereotaxic apparatus (David Kopf, Tujunga, CA). Constant infusion of supplemental anesthesia (chloral hydrate; $20-30 \mathrm{mg} \cdot \mathrm{kg}^{-1} \cdot \mathrm{hr}^{-1}$, i.p.) was maintained using a pump (Bioanalytical Systems, West Lafayette, IN). A bipolar concentric stimulating electrode (outer diameter, $1 \mathrm{~mm}$ ) with 0.5 $\mathrm{mm}$ of separation between the tips (Rhodes Medical Instruments, Woodland Hills, CA) was placed in the right medial PFC, $3 \mathrm{~mm}$ rostral to bregma, $1.6 \mathrm{~mm}$ lateral to the midline, and $4.3 \mathrm{~mm}$ ventral from the skull surface at a $30^{\circ}$ angle toward the midline. Using these coordinates, the electrode entered the brain in the left hemisphere and crossed the midline, with the electrode tip terminating in the prelimbic/infralimbic region of the right medial PFC. A second stimulating electrode was placed in the right VTA at $-6.0 \mathrm{~mm}$ anteroposterior, $0.5 \mathrm{~mm}$ lateral, and 7.4 $\mathrm{mm}$ ventral from the dural surface. Each electrode was connected to an Isoflex stimulus isolation unit (AMPI, Jerusalem, Israel) driven by a Master-8 stimulator (AMPI). Intracellular recording electrodes were pulled from borosilicate glass tubing (outer diameter, $1 \mathrm{~mm}$; World Precision Instruments, Sarasota, FL) using a P-97 Flaming-Brown microelectrode puller (Sutter Instruments, Novato, CA) to a resistance of $\sim 40-100 \mathrm{M} \Omega$ (measured in situ). Recording electrodes were filled with $2 \%$ Neurobiotin (Vector Laboratories, Burlingame, CA) in 2 or $3 \mathrm{M}$ potassium acetate and lowered into the right nucleus accumbens at the following range of coordinates: anteroposterior, $+1.2-1.8 \mathrm{~mm}$; lateral, $1.0-1.7 \mathrm{~mm}$; and dorsoventral, $5.5-7.5 \mathrm{~mm}$ from cortical surface. A hydraulic microdrive (Trent Wells, Coulterville, CA) was used to lower the recording electrode to the nucleus accumbens. Electrical signals from the recording electrode were transmitted via a headstage connected to an intracellular amplifier (IR-283; NeuroData, Delaware Water Gap, PA), and the recording signal was continuously monitored on a digital oscilloscope (TDS-220; Tektronix, Beaverton, OR). Intracellular signals were acquired and digitized at $10-20 \mathrm{kHz}$ via an interface board (DAP-3215; Microstar Labs, Bellevue, WA) installed in a Pentium III computer using customdesigned software (Neuroscope).

Experimental protocol. After stable impalement of a neuron, at least 5 min of baseline recording was collected. Only neurons exhibiting a stable membrane potential of at least $-50 \mathrm{mV}$ and an action potential amplitude of at least $40 \mathrm{mV}$ from threshold were used in this study. A series of positive and negative current injections $(0.1-0.5 \mathrm{nA} ; 100 \mathrm{msec})$ was administered to determine the input resistance and time constant of the cell $(\tau)$ (time to reach $63 \%$ of maximal voltage response to a negative current step). After these baseline recordings, the following stimulation protocol was applied once every $15 \mathrm{sec}$ for $10-15$ repetitions. A single-pulse stimulation of the PFC (0.6-1.0 mA; 0.5 msec; PFC1) was followed 500-900 msec later by train stimulation of the VTA $(20 \mathrm{~Hz}$ train of 5 pulses; 1.0
$\mathrm{mA} ; 0.5 \mathrm{msec}$ ). A second PFC pulse (PFC2), at the same intensity as the first, was then delivered $200 \mathrm{msec}$ after VTA train stimulation ended. This protocol was intended to assess the effect of PFC stimulation in the nucleus accumbens in the presence of dopamine released by VTA train stimulation resembling burst firing of dopamine neurons (SuaudChagny et al., 1995). Train stimulation of the VTA, rather than a pharmacological manipulation such as agonist administration, was used to more closely approximate the endogenous activation of VTA efferents, including the physiological time course and concentration of synaptic dopamine release in the accumbens. In some cells, systemic administration of DA antagonists ( $\mathrm{D}_{1}$ antagonist, $\mathrm{SCH} 23390,0.5 \mathrm{mg} / \mathrm{kg}, n=4$; or $\mathrm{D}_{2}$ antagonist, eticlopride, $0.5 \mathrm{mg} / \mathrm{kg}, n=7$ ) was used to confirm that the effects of VTA stimulation were attributable to activation of dopaminergic receptors. An additional set of stimulations was tested in a subset of neurons $(n=6)$, in which VTA stimulation in the combined protocol was replaced by a $500 \mathrm{msec}$ positive current injection $(0.05-0.17 \mathrm{nA})$ intended to mimic the level of membrane potential depolarization produced by VTA stimulation. In this protocol, the second PFC pulse (PFC2) was delivered $350 \mathrm{msec}$ after the onset of current injection. Again, the two PFC stimulations were delivered at the same intensity within each cell. In some cells, responses to PFC pulse stimulation and VTA train stimulation (20 $\mathrm{Hz}$ ) were also determined separately. In all of the cases, responses to stimulation were averaged over all of the repetitions delivered to the cell.

Histology. After the completion of recording, Neurobiotin was injected into the cell by passing positive current $(0.5-1.0 \mathrm{nA} ; 200 \mathrm{msec}$ pulses; 2 $\mathrm{Hz}$ ) for at least $10 \mathrm{~min}$ through the recording electrode. At the completion of the experiment, animals were euthanized with an overdose of pentobarbital $(100 \mathrm{mg} / \mathrm{kg})$ and transcardially perfused with cold saline followed by $4 \%$ paraformaldehyde. Brains were postfixed in $4 \%$ paraformaldehyde for at least $24 \mathrm{hr}$ before being transferred to a solution of $30 \%$ sucrose in $0.1 \mathrm{M}$ phosphate buffer for cryoprotection. After at least $2 \mathrm{~d}$ in sucrose buffer, sections were cut $(30-40 \mu \mathrm{m})$ using a freezing microtome and placed in phosphate buffer. Sections through the PFC and VTA were mounted on gelatin-coated slides and Nissl stained to verify placement of stimulating electrodes. Sections through the nucleus accumbens were processed for visualization of Neurobiotin-filled cells and, in some cases, were counterstained for calbindin immunoreactivity (anti-calbindin D-28K; 1:30,000; Vector Laboratories) to distinguish cell locations in the core and shell regions of the accumbens. After immunohistochemical processing, sections were mounted on gelatin-coated slides, cleared in xylenes, and coverslipped using Permount, and were then examined microscopically for cell location.

\section{Results}

\section{Electrophysiological properties of nucleus accumbens cells}

Intracellular recordings from 77 nucleus accumbens cells in 64 animals were analyzed and included in this study. Seventy of 77 (91\%) accumbens cells exhibited a membrane potential characterized by spontaneous fluctuations between two relatively steady values, a hyperpolarized down state and a more depolarized up state (Fig. 1A). In these neurons, the histogram distribution of membrane potential values over time could be fitted with high confidence to a dual Gaussian curve (Fig. $1 B$ ), and thus they were classified as bimodal. The up state in these neurons averaged $-70.0 \pm 8.8 \mathrm{mV}$ (mean $\pm \mathrm{SD})$, whereas the down state averaged $-84.3 \pm 7.4 \mathrm{mV}$. Up states were defined when the membrane potential value crossed a line set at approximately halfway between the down and up values as determined by the membrane potential histogram, and remained above this line for at least 100 msec. The duration of up states was $499.3 \pm 157.7 \mathrm{msec}$, and occurred at a frequency of $0.80 \pm 0.26 \mathrm{~Hz}$. Slightly more than one-half of these bimodal accumbens neurons were silent $(n=$ 38 ; $54 \%$ ); of those that did exhibit spontaneous action potential firing, the firing rate was $1.5 \pm 1.8 \mathrm{~Hz}$ (range, $0.04-7.5 \mathrm{~Hz}$ ). Action potential amplitude in all of the cells (spontaneous or evoked spikes, measured from threshold) averaged $47.3 \pm 5.5$ $\mathrm{mV}$. The input resistance (determined from the down state) of 

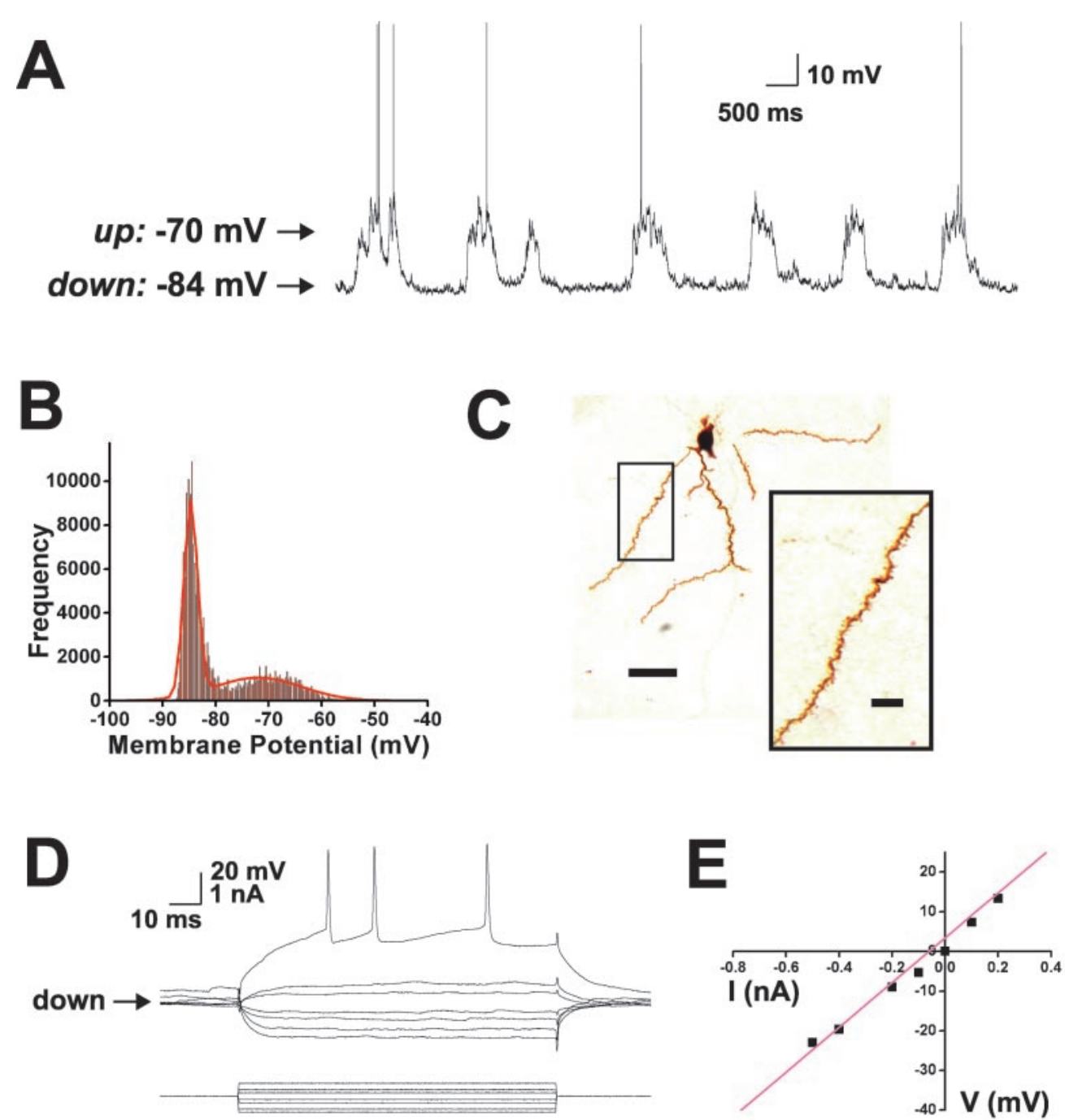

Figure 1. A majority (91\%) of neurons recorded in the nucleus accumbens exhibited a bimodal membrane potential. $A$, A representative trace from a bimodal neuron illustrating spontaneous oscillations between a hyperpolarized down state and depolarized up state, indicated by the arrows, at a frequency of $0.8 \mathrm{~Hz}$. The firing rate of this cell was $0.4 \mathrm{~Hz}$, with spikes occurring only during up states. $B$, Frequency distribution of membrane potential values for the neuron illustrated in $A$. This histogram could be fitted with high confidence $\left(R^{2}=0.94\right)$ to a bimodal Gaussian distribution, in which the two peaks correspond to the down and up states. C, Image of the cell illustrated in $A$, filled with Neurobiotin and visualized with immunohistochemistry. All of the recovered cells exhibited a morphology consistent with that of medium spiny neurons. Inset, Closer detail of spines on the indicated dendrite. Scale bars: C, $30 \mu \mathrm{m} ; C$, inset, $10 \mu \mathrm{m}$. D, Injection of alternating positive and negative current steps to the cell shown in $A$ produced characteristic voltage deflections, with the highest positive current culminating in spikes. E, Current-voltage plot for the traces shown in $D$. This cell had an input resistance of $51.8 \mathrm{M} \Omega$. For all of the cells, only current pulses that were delivered in the down state and did not result in spikes were included in the calculation of input resistance. In $D$, the most depolarized trace resulted in spikes and is shown for illustration only.

bimodal accumbens neurons $(n=61)$ was $87.1 \pm 30.8 \mathrm{M} \Omega$, with a time constant value $(\tau)$ of $4.7 \pm 1.6 \mathrm{msec}$.

The seven cells that did not exhibit a bimodal membrane potential had an average resting potential value of $-73.5 \pm 10.7$ $\mathrm{mV}$. In four of these seven cells, spontaneous fluctuations in the membrane potential could be observed, and these fluctuations resembled up states but did not meet the criteria of at least a $5 \mathrm{mV}$ difference between down and up values to be classified as bimodal. Five of the seven neurons were silent; the remaining two cells had firing rates of 0.3 and $0.4 \mathrm{~Hz}$. The amplitude of spontaneous or evoked action potentials, measured from threshold, in these cells was $49.7 \pm 6.9 \mathrm{mV}$. Input resistance was $86.6 \pm 24.1$ $\mathrm{M} \Omega$, and the time constant $(\tau)$ was $6.8 \pm 3.0 \mathrm{msec}$.

The location of all 77 neurons in the nucleus accumbens was verified on the basis of visualization of Neurobiotin-filled cells $(n=39)$ (Fig. 1C) or electrode tracks $(n=38)$ in sections counterstained for calbindin immunoreactivity. All of the
Neurobiotin-filled cells were medium-sized spiny neurons, as previously reported for accumbens neurons with up and down membrane potential states (O'Donnell and Grace, 1995). Of the 64 cells that could be definitively localized in the core or the shell, the majority ( $n=53$ ) were located in the core region, primarily the medial aspect, whereas 11 neurons were located in the shell. Similar proportions of neurons exhibited a bimodal membrane potential in the core $(n=48$ of $53 ; 91 \%)$ and shell (10 of 11 ; $91 \%$ ). Cells located in the core and shell did not differ substantially on any electrophysiological parameters, either basally or in response to any of the stimulation protocols described below, and thus were pooled for all of the data analyses.

\section{Response of nucleus accumbens cells to PFC or} VTA stimulation

Single-pulse stimulation of the PFC (0.5-1.0 mA) evoked an EPSP in 53 of 61 (87\%) accumbens neurons tested (Fig. 2 A). For 

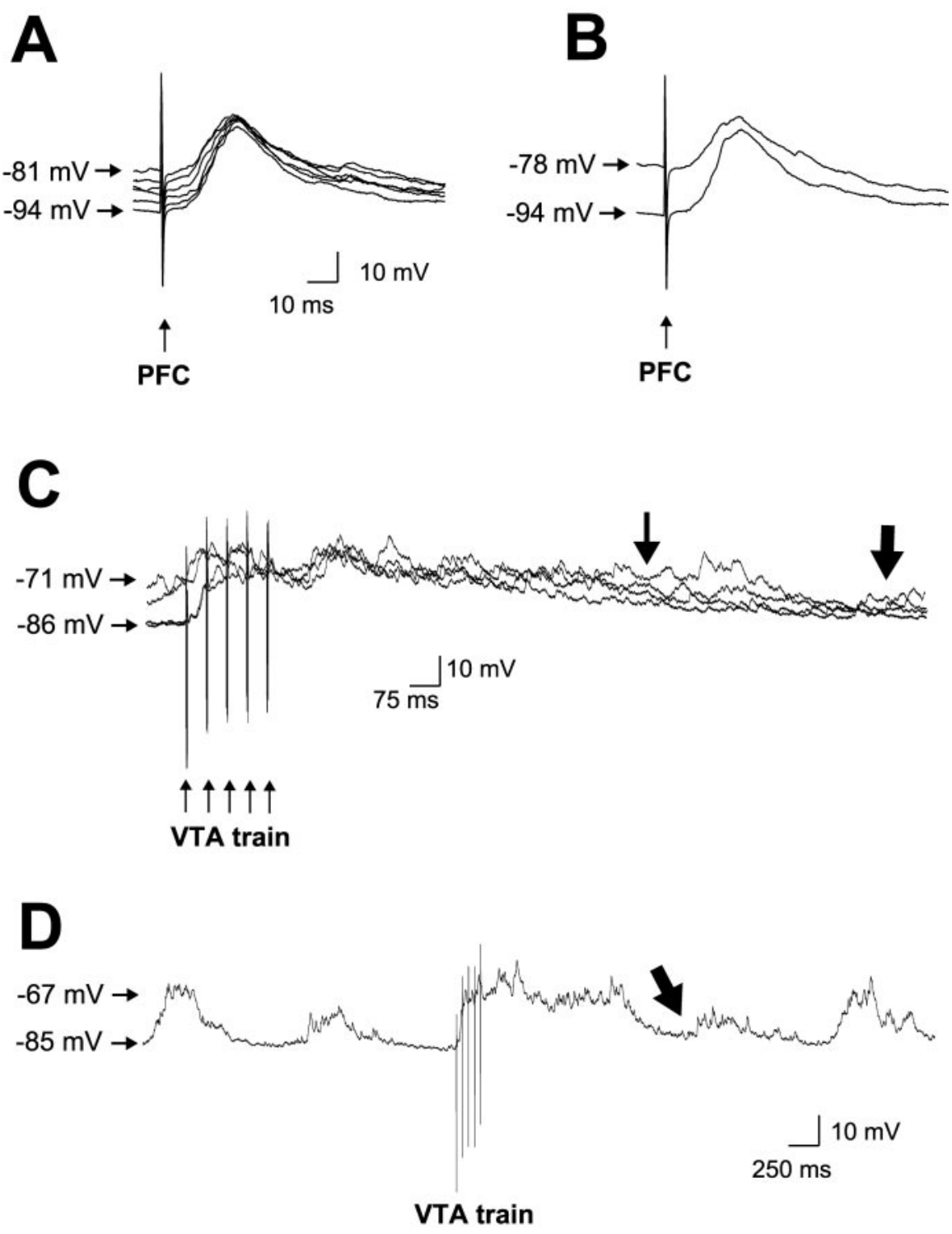

Figure 2. Single-pulse stimulation $(0.5-1.0 \mathrm{~mA} ; 0.5 \mathrm{msec})$ of the PFC elicited an EPSP, whereas train stimulation ( 5 pulses; 1.0 $\mathrm{mA} ; 20 \mathrm{~Hz}$ ) of the VTA evoked a sustained depolarization response in most accumbens neurons. $A, 0$ verlay of six repetitions of PFC stimulation (1.0 mA) to one cell. The average EPSP amplitude in this cell was $21.8 \mathrm{mV}$. B, Detail of PFC stimulations in the up and down state of the cell in $A$. In this cell, the average EPSP amplitude was $18.5 \mathrm{mV}$ from the up state and $27.1 \mathrm{mV}$ from the down state. C, Overlay of four repetitions of VTA train stimulation to another cell. VTA stimulation depolarized the membrane to a relatively consistent level regardless of whether the cell was in the up or down state at the time of stimulation. The average amplitude of the response in this cell was $20.0 \mathrm{mV}$ over all of the repetitions, and $25.2 \mathrm{mV}$ from the down state. The average time to decay to one-half amplitude was $923 \mathrm{msec}$ (thin arrow), and the duration to return to baseline was $1532 \mathrm{msec}$ (thick arrow). $D$, After the termination of this sustained depolarization, most cells were observed to return to spontaneous membrane potential shifts (arrow, onset of a transition to an up state).

each neuron, the intensity of PFC stimulation was set to elicit an EPSP at or just below maximal amplitude, based on the response to a range of stimulation intensities not exceeding 1.0 mA. EPSP amplitudes averaged $14.7 \pm 7.2 \mathrm{mV}$, but were fairly variable across cells (range, 5.1-38.8 mV). The onset latency of PFCevoked EPSPs was 9.9 $\pm 3.5 \mathrm{msec}$ (range, 2.2-20.7 msec), and the decay to one-half amplitude was $19.1 \pm 7.8 \mathrm{msec}$ (range, 8.2$44.3 \mathrm{msec}$ ). In bimodal cells in which a sufficient number of stimulations were delivered during spontaneous up and down states (Fig. 2 B), the amplitude of PFC-evoked EPSPs was $12.9 \pm$ $6.1 \mathrm{mV}$ during the up state $(n=37)$ and $17.7 \pm 7.9 \mathrm{mV}$ during the down state $(n=35)$. In a few cells $(n=10)$, PFC stimulation could evoke an action potential, but only if the cell was in the up state when the pulse was delivered, in accordance with previous results (O'Donnell and Grace, 1995).

Train stimulation of the VTA evoked a sustained membrane depolarization in 36 of 39 cells tested (92\%) (Fig. 2C), in agreement with our previous findings (Goto and O'Donnell, 2001). Unlike the response to PFC stimulation, the response to VTA train stimulation did not appear to depend qualitatively on resting membrane potential state (Fig. $2 D$ ) (i.e., there was no spike firing observed when cells were stimulated in the up state). However, across repeated trials in bimodal cells, VTA stimulation typically produced a depolarization that was close to the observed up state for that cell, resulting in a variable response amplitude depending on whether the cell was in the down or the up state at the beginning of train stimulation. Thus, averaged over all of the repetitions in all of the cells, the peak amplitude of the response to VTA stimulation was $10.5 \pm 4.8$ $\mathrm{mV}$, whereas the response amplitude computed selectively from repetitions stimulated in the down state $(n=33)$ averaged $16.5 \pm 6.2 \mathrm{mV}$. This latter value was similar to the amplitude of spontaneous up states observed in these neurons (15.4 \pm $6.5 \mathrm{mV})$. The depolarization elicited by VTA train stimulation exhibited a decay to one-half amplitude of $644.9 \pm 372.9 \mathrm{msec}$, and returned to the prestimulation baseline membrane potential level after $1227.4 \pm 413.7 \mathrm{msec}$ (Fig. 2C). After this depolarization response, a return to spontaneous up and down fluctuations could be observed in many cells (Fig. 2D). No action potential firing was observed during the VTA-evoked depolarization in 35 of the 36 cells that exhibited a response.

\section{PFC-elicited responses before and after VTA train stimulation}

To assess the effect of VTA activation on the response to PFC stimulation, characteristics of PFC-elicited EPSPs before and after train stimulation of the VTA (in the same cell) were compared in 48 cells. After VTA train stimulation, the amplitude of the PFC-evoked EPSP (PFC2) was significantly smaller than the PFC-evoked EPSP at baseline $(\mathrm{PFC} 1)\left(t_{(47)}=8.65 ; p<0.001\right)$ (Fig. $\left.3 A, B\right)$, with the second EPSP amplitude averaging $67 \%$ of the first. The onset latency of PFC responses was not affected by VTA stimulation (Fig. $3 B)\left(t_{(47)}\right.$ $=0.05 ; p=0.962)$, but the time for EPSPs to decay to one-half amplitude was shortened $(B)\left(t_{(47)}=7.06 ; p<0.001\right)$.

To address the possibility that EPSP amplitude diminished as a result of repeated PFC stimulation, VTA train stimulation was not delivered between PFC stimulations in a subset of cells $(n=$ 9) (Fig. 3C). Under these control conditions, no attenuation in amplitude was observed from the first to the second PFC-elicited 
$\operatorname{EPSP}\left(t_{(8)}=0.55 ; p=0.596\right)$ (Fig. $\left.3 D\right)$. The onset latency of the EPSPs evoked by PFC stimulation was also unchanged in the absence of intervening VTA stimulation (Fig. 3D) $\left(t_{(8)}=0.60 ; p=0.565\right)$, as was the decay to one-half amplitude of the response $(D)\left(t_{(8)}=1.63 ; p=0.142\right)$. Thus, train stimulation of the VTA, using parameters similar to those that evoke terminal dopamine release (Suaud-Chagny et al., 1995), potently reduced the amplitude and decay time of PFC-evoked EPSPs in accumbens cells, and this effect was independent of short-term changes in responsivity to PFC stimulation.

\section{Effect of membrane depolarization on PFC-elicited responses}

Because VTA train stimulation produced a sustained depolarization in nucleus accumbens cells (Fig. 2C,D), it is possible that the reduction in the amplitude of PFC-elicited EPSPs after VTA stimulation is simply a reflection of a voltage dependence of the PFC response. PFC stimulation delivered at the more depolarized membrane potential values observed after VTA stimulation might have elicited smaller EPSPs because of intrinsic membrane properties, rather than resulting from a dopaminergic suppression of the synaptic response. As described below, two approaches were taken in an effort to address these possibilities.

\section{Spontaneous up states versus}

VTA-evoked depolarization

A subset $(n=26)$ of the cells described in the previous section was identified in which at least two stimulation repetitions contained a baseline PFC stimulation (PFC1) that was delivered during a spontaneous up state. Thus, the first and second PFC stimulations in these repetitions were delivered at more comparable levels of membrane depolarization (up state, $-73.4 \pm 8.5 \mathrm{mV}$; VTA-evoked, $-70.5 \pm$ $8.1 \mathrm{mV}$ ) (Fig. 4A). When the statistical analysis was limited to these cases $(2-10$ repetitions per cell), the amplitude of the second PFC-elicited EPSP, after VTA train stimulation, remained significantly attenuated in comparison with the first EPSP elicited during a spontaneous up state $\left(t_{(25)}=5.48 ; p<0.001\right)$ (Fig. $\left.4 B\right)$. Similarly, onset latencies were again unaffected (Fig. $4 B)\left(t_{(25)}=1.68 ; p=0.104\right)$, whereas the decay to one-half amplitude was attenuated $\left(t_{(25)}=4.04 ; p<\right.$ $0.001)(B)$.

\section{PFC-elicited responses before and after intracellular} current injection

The relationship between EPSP amplitude and membrane depolarization was further investigated in eight cells by replacing train stimulation of the VTA with depolarizing current injected

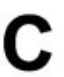

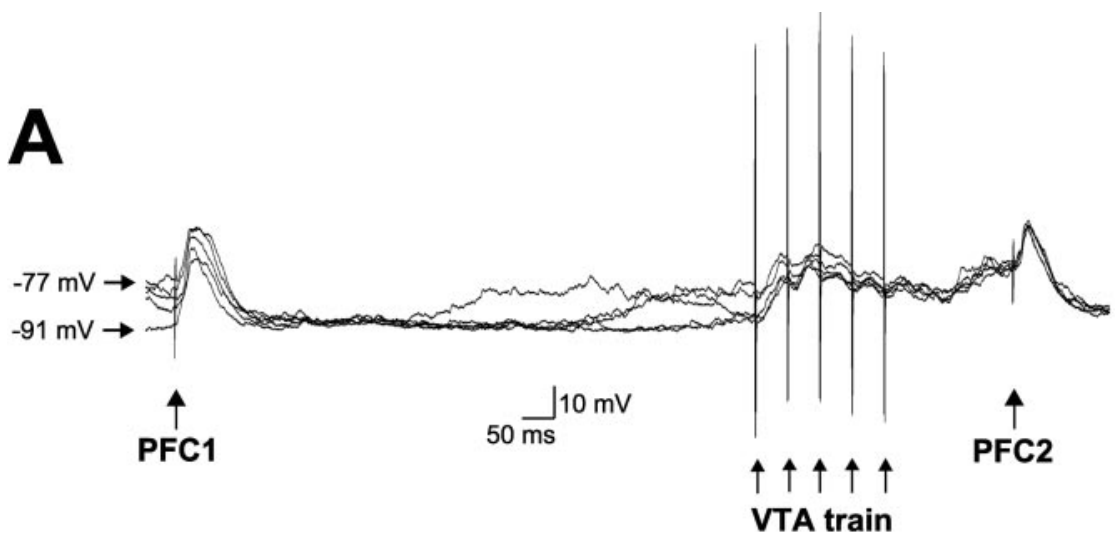
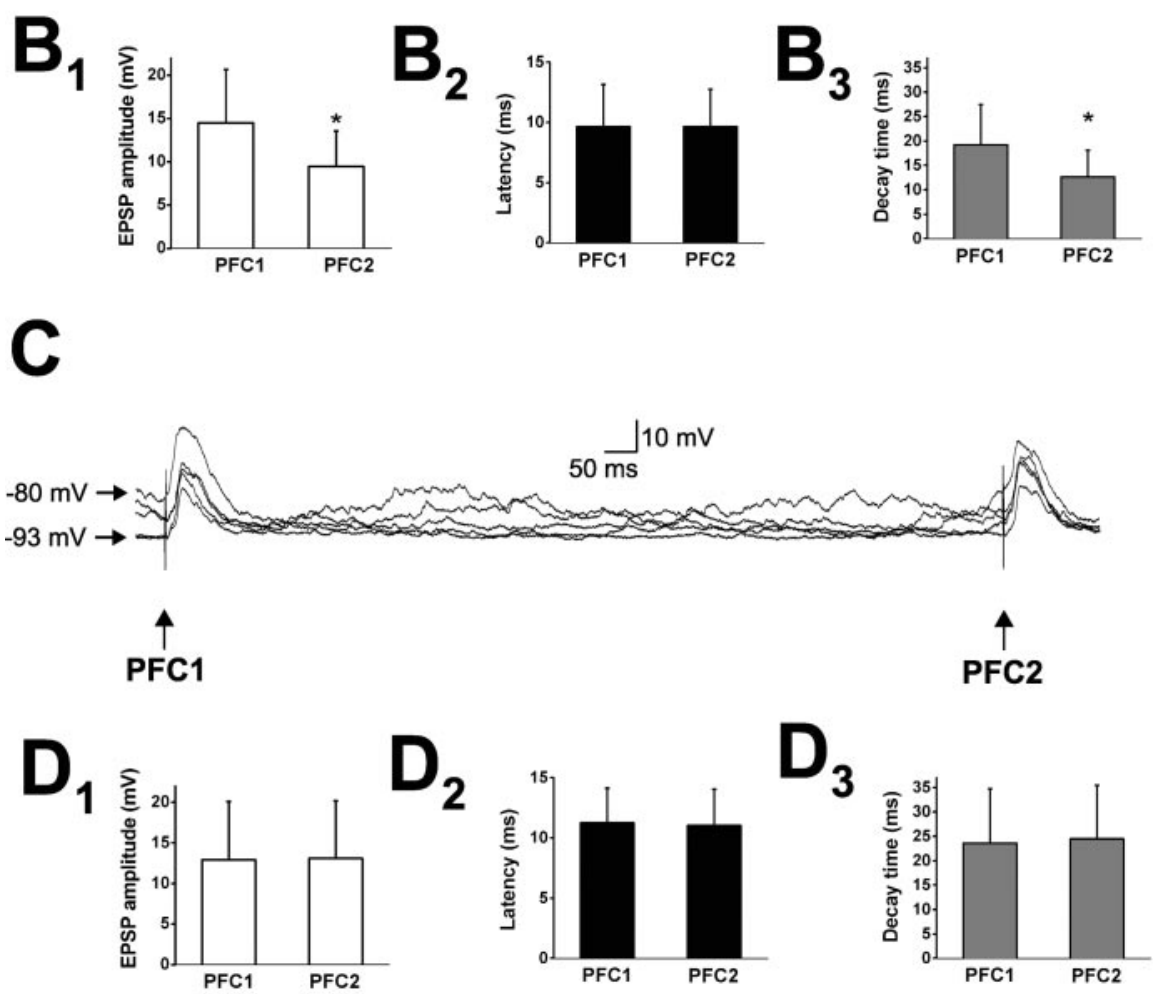

Figure 3. VTA train stimulation reduced the amplitude of PFC-evoked EPSPs. A, Overlay of five traces from one cell illustrating stimulation with the combined protocol as described in Materials and Methods. In this neuron, train stimulation of the VTA (5 pulses; $1.0 \mathrm{~mA} ; 20 \mathrm{~Hz})$ was initiated $900 \mathrm{msec}$ after PFC1 $(0.8 \mathrm{~mA})$, and PFC2 $(0.8 \mathrm{~mA})$ was delivered $200 \mathrm{msec}$ after the last pulse of the VTA train. The amplitude of the response to PFC2 in this cell averaged $82.5 \%$ of the response to PFC1 over all of the repetitions. $B$, Summary of results from all 48 cells (mean + SD) showing a significant reduction in EPSP amplitude (B1), a lack of effect on onset latencies (B2), and a significant reduction in decay to one-half amplitude (B3) of PFC-elicited EPSPs after VTA train stimulation. Error bars in $B$ and $D$ represent SDs from the mean. $C$, Traces from the same neuron as in $A$ illustrating that PFC EPSP amplitude was not reduced in the absence of VTA train stimulation. Five traces from this cell are overlaid. The PFC2 pulse stimulation $(0.8 \mathrm{~mA})$ was delivered $1300 \mathrm{msec}$ after PFC1 (0.8 mA). The amplitude of the EPSP in response to PFC2 averaged $91 \%$ of the response to PFC1 in this cell. D, Summary of results from all nine cells, illustrating that EPSP amplitude (D1), onset latency (D2), and decay time (D3) were unchanged over time in the absence of VTA stimulation. ${ }^{*} p<0.001$.

through the recording electrode. The current level (0.05-0.18 $\mathrm{nA}$ ) was determined independently for each cell to approximate the depolarizing response to VTA stimulation for that cell. The level of membrane depolarization evoked by positive current injection $(6.2 \pm 2.8 \mathrm{mV})$ was similar to that elicited by VTA train stimulation $(6.5 \pm 4.0 \mathrm{mV})$ in these cells. However, there was no significant change in the amplitude of PFC-elicited EPSPs after intracellular injection of positive current $\left(t_{(7)}=0.13 ; p=0.9\right.$ ) (Fig. 5). In further contrast to the effects of VTA stimulation, the time for EPSPs to decay to one-half amplitude was significantly 


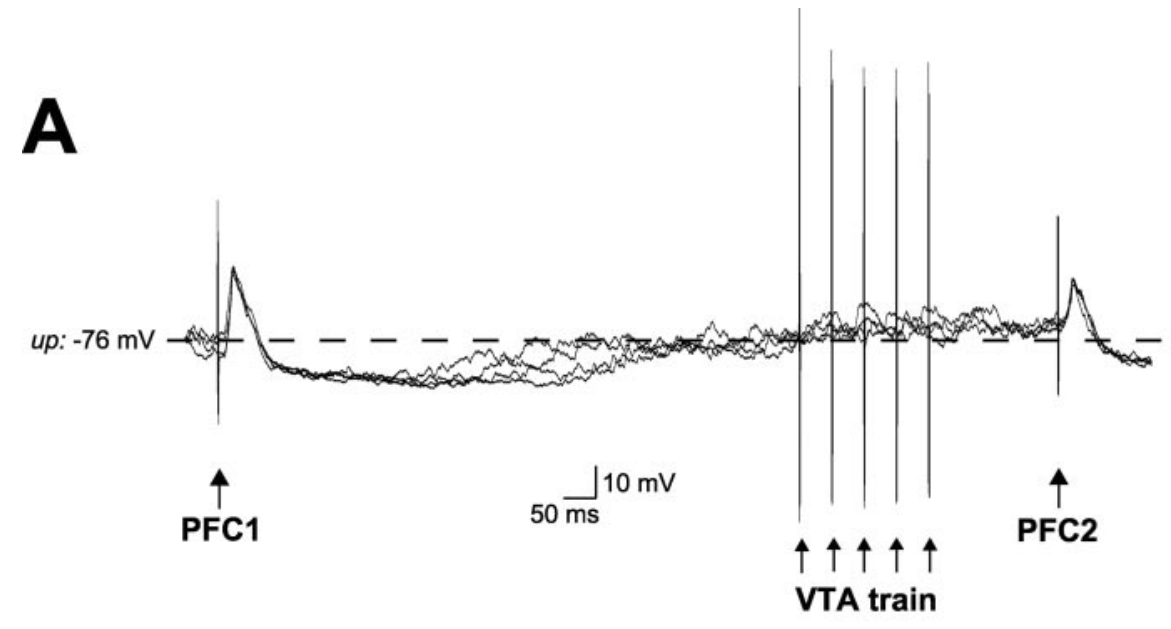

$B_{1}$

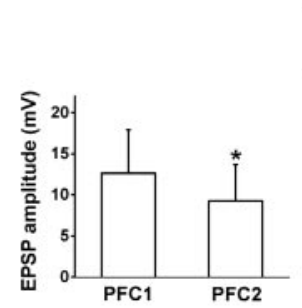

$B_{2}$
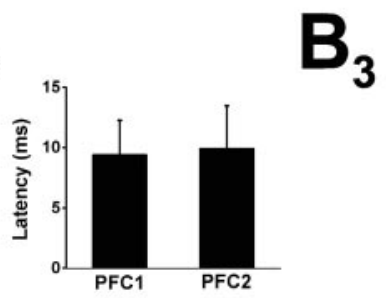

Figure 4. PFC-evoked EPSPS after VTA train stimulation were also attenuated when selectively compared with EPSPs elicited during spontaneous up states. $A$, Overlay of four traces illustrating that PFC stimulation (PFC1) (1.0 mA) delivered during a spontaneous up state (indicated by arrow and dashed line) evoked an EPSP with a larger amplitude than PFC stimulation delivered after VTA train stimulation (PFC2) $(1.0 \mathrm{~mA})$. In this cell, the amplitude of the response to PFC2 averaged $59 \%$ of the response to PFC1. $B$, Summary of comparisons between PFC1 in up states and PFC2 after VTA stimulation in 26 cells showing that EPSP amplitude (B1) was significantly attenuated despite comparable levels of membrane depolarization. Onset latencies (B2) were unaffected, whereas decay to one-half amplitude times $(B 3)$ were also significantly reduced after VTA stimulation compared with EPSPs evoked during up states. ${ }^{*} p<0.05$. Error bars represent SDs from the mean.

increased after positive current injection $\left(t_{(7)}=2.69 ; p=0.031\right)$ (Fig. $5 B$ ), whereas response onset latencies remained unaffected (B) $\left(t_{(7)}=1.02 ; p=0.34\right)$.

Thus, although intracellular current injection depolarized the membrane in a similar manner as train stimulation of the VTA, it had markedly different effects on the response of accumbens cells to PFC stimulation. The amplitude of PFC-evoked EPSPs was not attenuated, and the decay times of the responses were lengthened. Together with the comparison between spontaneous up states and VTA-evoked depolarizations described in the preceding paragraph, these results suggest that the ability of VTA train stimulation to reduce the amplitude of PFC-evoked EPSPs in accumbens cells is not simply a consequence of the membrane potential depolarization produced by VTA stimulation.

\section{Effect of DA receptor antagonists on PFC-elicited responses}

To verify that the reduction in PFC EPSP amplitude after VTA stimulation was caused by activation of dopaminergic fibers, the combined PFC and VTA stimulation described above was repeated in some cells after systemic administration of a $\mathrm{D}_{1}$ antagonist ( $\mathrm{SCH} 23390 ; 0.5 \mathrm{mg} / \mathrm{kg}$, i.p.; $n=4$ ) or a $\mathrm{D}_{2}$ antagonist (eticlopride; $0.5 \mathrm{mg} / \mathrm{kg}$, i.p.; $n=7$ ). Repeated-measures ANOVA was used to compare PFC response parameters before and after VTA stimulation over three time periods (predrug, postdrug1, and postdrug2). The "postdrug1" time period consisted of stimulations conducted at 9-13 min after drug administration, and the "post-

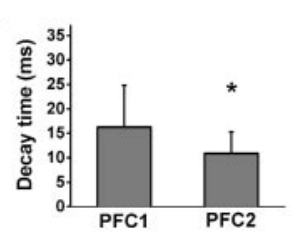

drug2" time period corresponded to stimulations delivered at $18-24 \mathrm{~min}$ after drug injection.

Systemic administration of SCH 23390 ( $0.5 \mathrm{mg} / \mathrm{kg}$, i.p.) had no effect on the VTAevoked reduction of PFC response amplitudes (Fig. 6A, $B$ ), as evidenced by the lack of a significant interaction between PFC stimulation and postdrug time $\left(F_{(2,6)}=\right.$ $1.18 ; p=0.371)$. Similar to the effect described above, PFC EPSP amplitude remained attenuated after VTA stimulation when collapsed across all of the time points, as illustrated by a significant main effect of PFC stimulation $\left(F_{(1,3)}=15.0\right.$; $p=0.03$ ) (Fig. 6C). SCH 23390 also did not change the relationship between $\mathrm{PFC}$ response onset latencies $\left(F_{(2,6)}=0.21 ; p=\right.$ $0.819)$ or decay times $\left(F_{(2,6)}=1.31 ; p=\right.$ 0.338 ) before and after VTA stimulation (data not shown). Comparison of the amplitudes of PFC EPSPs elicited during spontaneous up states with those elicited during the VTA-evoked depolarizations similarly revealed no effect of SCH 23390 (Fig. 6A,B) $\left(F_{(2,6)}=1.40 ; p=0.316\right)$. Across all of the time points, PFC-elicited EPSPs were dampened after VTA stimulation when compared with EPSPs occurring during spontaneous up states $\left(F_{(1,3)}=\right.$ 9.82; $p=0.05$ ) (Fig. 6D). These results suggest that the reduction of PFC response amplitudes by VTA train stimulation is not mediated by actions at $\mathrm{D}_{1}$ receptors.

Eticlopride $(0.5 \mathrm{mg} / \mathrm{kg}$, i.p.) blocked the ability of VTA stimulation to attenuate the PFC-evoked response (Fig. 7A,B). However, this effect was observed only on EPSPs evoked at depolarized membrane potentials (up states; $F_{(2,10)}=7.63 ; p=$ 0.01 ). Paired $t$ tests revealed that PFC response amplitude was significantly attenuated after VTA stimulation during the predrug period $\left(t_{(5)}=2.87 ; p=0.035\right)$, but not during either the first or the second postdrug time periods (postdrug1, $t_{(5)}=1.80, p=$ 0.132 ; postdrug2, $\left.t_{(5)}=0.81, p=0.453\right)$ (Fig. $\left.7 D\right)$. This effect was limited to stimulation repetitions in which PFC1 was delivered during a spontaneous up state, because the overall analysis including all of the stimulation repetitions did not result in a significant interaction $\left(F_{(2,12)}=1.52 ; p=0.259\right)$. When all of the repetitions were included, the amplitude of PFC EPSPs remained significantly decreased after VTA stimulation across all of the time points $\left(F_{(1,6)}=\right.$ 27.36; $p=0.002$ ) (Fig. 7C). Onset latencies before and after VTA stimulation were unaffected by eticlopride $\left(F_{(2,12)}=1.88 ; p=\right.$ $0.195)$, as were the decay times to one-half amplitude $\left(F_{(2,12)}=1.30\right.$; $p=0.308$; data not shown). Together, this pattern of results indicates that the attenuation of PFC responses by VTA stimulation is at least partially mediated by the activation of $\mathrm{D}_{2}$ receptors.

\section{Discussion}

In nucleus accumbens neurons recorded in vivo, stimulation of the VTA in a pattern resembling dopamine cell burst firing decreased the amplitude of synaptic responses evoked by PFC stimulation. The attenuation of PFC responses could not be fully attributed to differences in resting membrane potential, because 
positive current injection did not attenuate the amplitude of PFC-elicited EPSPs. In addition, EPSPs elicited during VTA stimulation-evoked depolarizations were consistently smaller than EPSPs elicited during comparable periods of spontaneous depolarization (up states). This difference was reversed by $\mathrm{D}_{2}$, but not $\mathrm{D}_{1}$, receptor blockade. These results provide the first in vivo evidence that activation of dopaminergic projections dampens the response of accumbens neurons to prefrontal inputs via $\mathrm{D}_{2}$ receptors.

\section{VTA modulation of cortical inputs to the nucleus accumbens}

Stimulation of the VTA decreased both the amplitude and decay time of EPSPs elicited by PFC stimulation. This suggests that, when VTA neurons are activated, descending PFC inputs to the accumbens will elicit responses that are less likely to summate and reach firing threshold. Because PFC afferents appear to provide the primary drive on accumbens output cell firing, this attenuation would substantially decrease the flow of information that is transmitted back to the PFC through pallidal and thalamic areas (O'Donnell and Grace, 1995).

The reduction of accumbens responses to PFC input by VTA stimulation in vivo supports and extends previous findings that dopamine modulates the effects of excitatory afferent inputs. Stimulation of the VTA in vivo or activation of dopamine receptors in vitro attenuates the responses of accumbens neurons to stimulation of the amygdala or hippocampus (Yang and Mogenson, 1984; Yim and Mogenson, 1988; Charara and Grace, 2003). The amplitude of PFC-evoked EPSPs is also decreased after application of dopamine agonists in vitro (Pennartz et al., 1992; O'Donnell and Grace, 1994; Harvey and Lacey, 1996). Thus, as proposed by Mogenson et al. (1988), the primary function of dopamine in the nucleus accumbens appears to be to modulate the effects of excitatory limbic and cortical inputs rather than to drive neuronal activity directly (O’Donnell, 1999; Nicola et al., 2000).

\section{Mechanisms of dopaminergic modulation of PFC inputs}

The amplitude of PFC-evoked responses was consistently attenuated by VTA train stimulation, in comparison with PFC stimulations occurring in either the down or the up state. However, $\mathrm{D}_{2}$ receptor blockade only reversed this decrease in comparison with PFC stimulations delivered in the up state. This finding suggests that the attenuation of PFC responses by VTA stimulation is likely to be mediated by both dopaminergic and nondopaminergic components. The nondopaminergic attenuation of PFC responses is unlikely to be caused by the depolarization of the membrane potential per se, because intracellular current injection did not reproduce the decrease in PFC-elicited EPSP amplitude. Furthermore, we recently demonstrated that the amplitude of PFC responses is actually maximal at more depolarized membrane potentials (Goto and O'Donnell, 2002). Finally, there is a GABAergic projection from the VTA to the nucleus accumbens
(Van Bockstaele and Pickel, 1995), raising the possibility that the depression of PFC inputs may be partially mediated by GABA. However, although it is likely that the initial VTA-evoked plateau depolarization includes a fast GABA-mediated component, the reduction in PFC input was observed 200 msec after the train stimulation, at a time point when the effects of GABA have most likely subsided and dopamine is acting to sustain the duration of the response (Goto and O'Donnell, 2001).

The state-dependent effects of $\mathrm{D}_{2}$ receptor blockade suggest that increased dopamine release in the nucleus accumbens can contribute to dampening PFC inputs via $\mathrm{D}_{2}$ receptor activation, and confirms previous in vitro findings that $\mathrm{D}_{2}$ receptors exert a tonic attenuation of cortical inputs to accumbens neurons (O'Donnell and Grace, 1994). Although previous in vitro experiments have reported a selective modulation of PFC inputs to the accumbens by a $\mathrm{D}_{1}$-like mechanism (Pennartz et al., 1992; Harvey and Lacey, 1996; Nicola et al., 1996), we found no evidence for a role of $D_{1}$ receptors in the suppression of prefrontal inputs in vivo, using a selective $\mathrm{D}_{1}$ antagonist ( $\mathrm{SCH} 23390$ ) at a dose that effectively attenuates responses to VTA stimulation in PFC pyramidal neurons (Lewis and O'Donnell, 2000) or, in conjunction with a $\mathrm{D}_{2}$ antagonist, in accumbens neurons (Goto and O’Donnell, 2001). Differences between recording conditions, specific antagonists, and/or placement of recording and stimulating electrodes could account for these disparities. For example, Pennartz et al. (1992) pooled the responses to local, fornix, and cortical stimulation in their investigation of the dopaminergic 


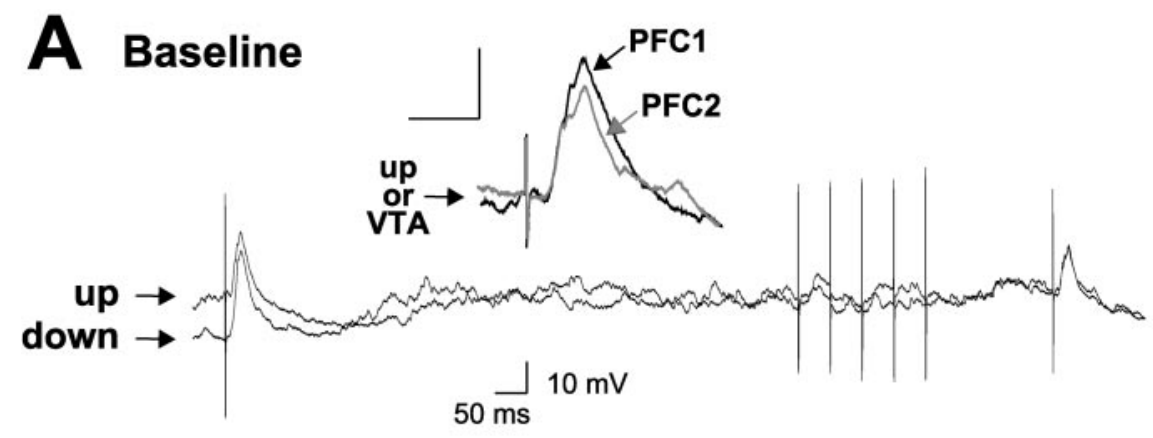

\section{B ScH 23390}
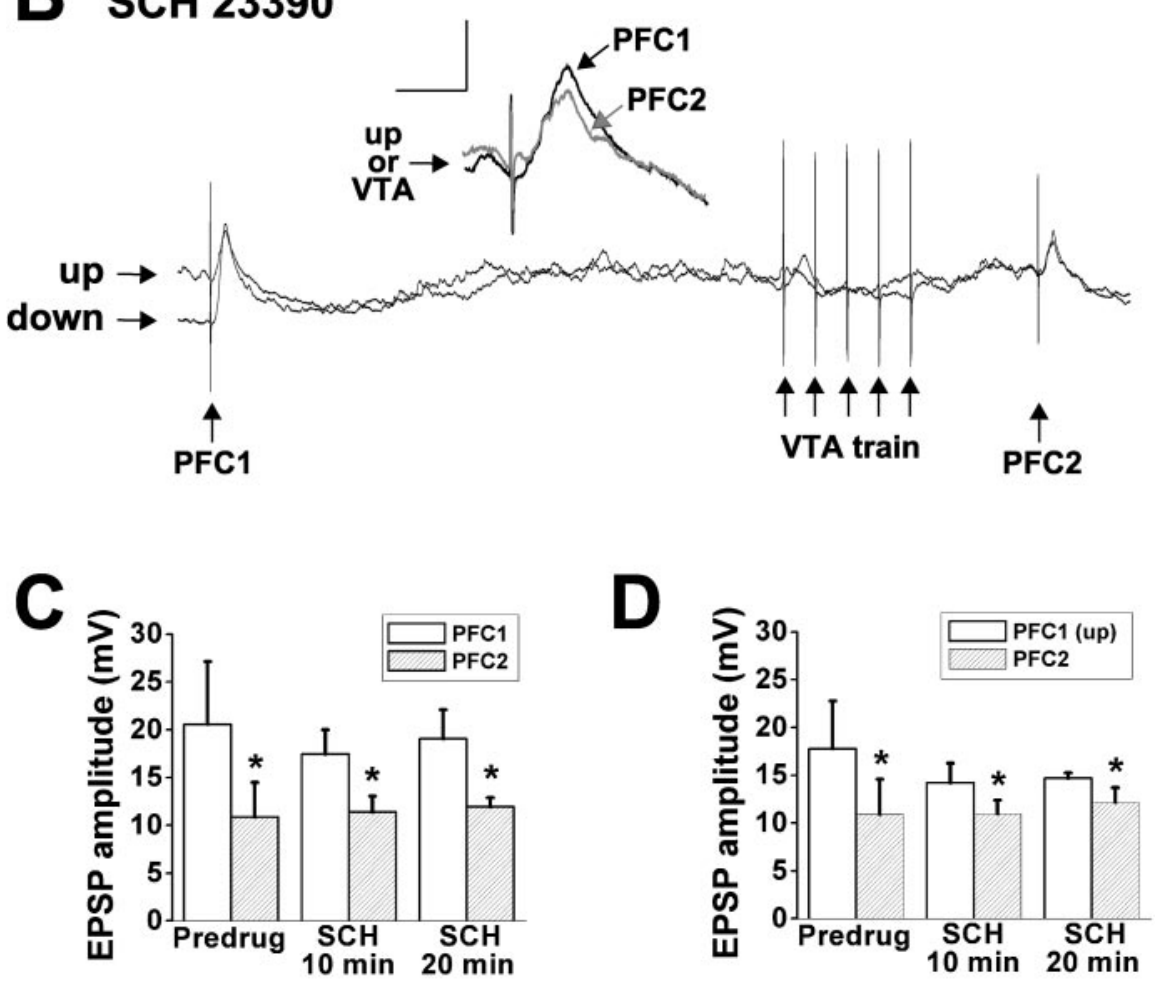

Figure 6. Systemic administration of the $D_{1}$ antagonist $S C H 23390(0.5 \mathrm{mg} / \mathrm{kg}$, i.p.) did not alter the attenuation of PFC-evoked responses after VTA train stimulation. $A$, Overlay of two traces from the up and down states of one cell illustrating the baseline (predrug) response to combined PFC (1.0 mA) and VTA train stimulation. Over all of the repetitions, the amplitude of the response to PFC2 in this cell averaged $72.6 \%$ of the response to PFC1. Inset, Detail of the EPSPs evoked by the first PFC stimulation (PFC1; black) during a spontaneous up state and the second PFC stimulation (PFC2; gray) during the VTA-elicited plateau. The EPSP amplitude in response to PFC2 averaged $86.3 \%$ of the PFC1 EPSP amplitude, when PFC1 stimulation occurred during a spontaneous up state. B, Overlay of two traces from the same cell as in $A$ during the second postdrug time period ( 20 min after SCH 23390 injection). After drug administration, the amplitude of the response to PFC2 averaged $62.8 \%$ of the response to PFC1, over all of the repetitions. Inset, Detail of EPSPs as in A, illustrating that, in the presence of SCH 23390, the amplitude of PFC-elicited EPSPS was still decreased by VTA stimulation (PFC2 $=77.5 \%$ of PFC1), in comparison with spontaneous up states. Calibration: (in insets) $10 \mathrm{mV}, 30 \mathrm{msec}$. C, Summary of results from all of the cells $(n=4)$ illustrating that PFC response amplitude remained attenuated after VTA stimulation, across all three predrug and postdrug time points, when all of the stimulation repetitions were analyzed. Labeled time points on the abscissa represent a range of times postdrug ( $10 \mathrm{~min}=10-11 \mathrm{~min} ; 20 \mathrm{~min}=19-21 \mathrm{~min})$. Error bars in C and D represent SDs of the mean. D, Summary of results from all of the cells, illustrating the failure of SCH 23390 to block the attenuation of PFC responses when analysis was limited to PFC stimulations occurring during up states. ${ }^{*} p<0.05$ (main effect of PFC stimulation) $(C, D)$.

suppression of synaptic responses. The recent finding that responses to stimulation of hippocampal or amygdaloid afferents are attenuated by $\mathrm{D}_{1}$ (but not $\mathrm{D}_{2}$ ) receptor activation (Charara and Grace, 2003) suggests that previous results may have been skewed by activation of non-prefrontal afferents.

It has been speculated that the depolarization produced by
VTA train stimulation is a direct postsynaptic effect in accumbens neurons, whereas the modulation of excitatory inputs may be attributable to presynaptic reduction of glutamate release from afferent terminals (Mogenson et al., 1988; Yim and Mogenson, 1988). Such a dissociation may explain why the attenuation of PFC responses can be partially blocked by $\mathrm{D}_{2}$ antagonism alone, whereas the plateau depolarization in response to VTA train stimulation is shortened only by combined $\mathrm{D}_{1}$ and $\mathrm{D}_{2}$ receptor blockade (Goto and O'Donnell, 2001). In vitro experiments, which allow for a more thorough investigation of presynaptic and postsynaptic mechanisms, have supported a presynaptic locus of action for dopamine in modulating synaptic responses, because accumbens neurons do not show consistent changes in input resistance or postsynaptic currents after application of dopamine (O'Donnell and Grace, 1994; Harvey and Lacey, 1996; Nicola et al., 1996). Although dopaminergic afferents do not make clear axoaxonic synaptic contacts on excitatory terminals in the nucleus accumbens (Sesack and Pickel, 1992), dopamine may diffuse extrasynaptically (Garris et al., 1994) to act at receptors reportedly localized on descending cortical terminals in the nucleus accumbens and striatum (Tarazi and Baldessarini, 1999). Additionally, the closely apposed convergence of dopamine terminals and PFC afferents on spiny dendrites of accumbens neurons (Sesack and Pickel, 1992) provides an anatomical basis for postsynaptic integration of dopaminergic and glutamatergic signaling.

\section{Functional considerations}

Although accumbens neurons were depolarized by VTA stimulation, the synaptic response to PFC stimulation was significantly attenuated. A dual effect of dopamine was also observed in accumbens neurons with respect to amygdala stimulation (Yim and Mogenson, 1988) or intracellular current injection (O'Donnell and Grace, 1996). Furthermore, spike firing, which is likely to be driven by PFC afferents (O'Donnell and Grace, 1995), is generally suppressed during the membrane depolarization evoked by VTA stimulation (Yim and Mogenson, 1988; Goto and O'Donnell, 2001). In contrast, stimulation of glutamatergic inputs in the fimbria-fornix produces a sustained depolarization in accumbens neurons, but is characterized by increased spike firing and responsiveness to PFC inputs, and thus resembles an up state (O'Donnell and Grace, 1995). Stimulation of the VTA drives accumbens cells into a depolarized state 
that is near the membrane potential value of an up state, but is paradoxically less responsive to activation of other excitatory inputs and is therefore qualitatively dissimilar to a spontaneous or hippocampal-evoked up state. Thus, the hippocampus appears to gate prefrontal input in a permissive manner (O’Donnell and Grace, 1995), whereas dopamine imposes a more restrictive filter on cortical inputs to accumbens neurons (O’Donnell, 2003).

Dopamine transmission in the nucleus accumbens is hypothesized to mediate the selection and integration of cortical, hippocampal, and amygdaloid inputs to medium spiny neurons, thus determining the pattern of information transmission to output areas and ultimately influencing response selection (Mogenson et al., 1988; Pennartz et al., 1994, 1999; Meredith and Totterdell, 1999; Floresco et al., 2001). Such a selection process may be accomplished by a dopaminergic enhancement of the signal-to-noise ratio in accumbens neurons (DeFrance et al., 1985; Kiyatkin and Rebec, 1996; O’Donnell and Grace, 1996; Nicola et al., 2000). In behaviorally relevant contexts, increased dopamine transmission may reduce background activity and suppress responses to weak or irrelevant inputs in accumbens cells, while facilitating transmission from contextually appropriate inputs (Mogenson et al., 1988; Pennartz et al., 1994; O’Donnell and Grace, 1996; Nicola and Malenka, 1997). The selective modulation of prefrontal inputs by $\mathrm{D}_{2}$ receptors and limbic inputs by $\mathrm{D}_{1}$ receptors provides a possible mechanism for such a process (Charara and Grace, 2003). In this context, the results reported here suggest that, in situations that increase accumbens dopamine transmission by driving VTA cell burst firing, PFC inputs that would normally elicit a subthreshold synaptic response are attenuated, conceivably because they are not relevant to the current behavioral or cognitive context. In these situations, corticoaccumbens inputs may need to be stronger or more synchronous to be selected, perhaps arising from coincident activity in multiple prefrontal areas or in other limbic areas (Groenewegen et al., 1999). The dopaminergic selection of afferent inputs for information processing in the nucleus accumbens may mediate response selection by shaping ensembles of accumbens neurons that subserve diverse behavioral and cognitive functions (Pennartz et al., 1994; Meredith and Totterdell, 1999; O'Donnell, 1999, 2003), and may ultimately translate into processes such as reward learning (Schultz, 1998) or the attribution of incentive salience (Berridge and Robinson, 1998). Dysfunctions in dopaminergic transmission could result in the
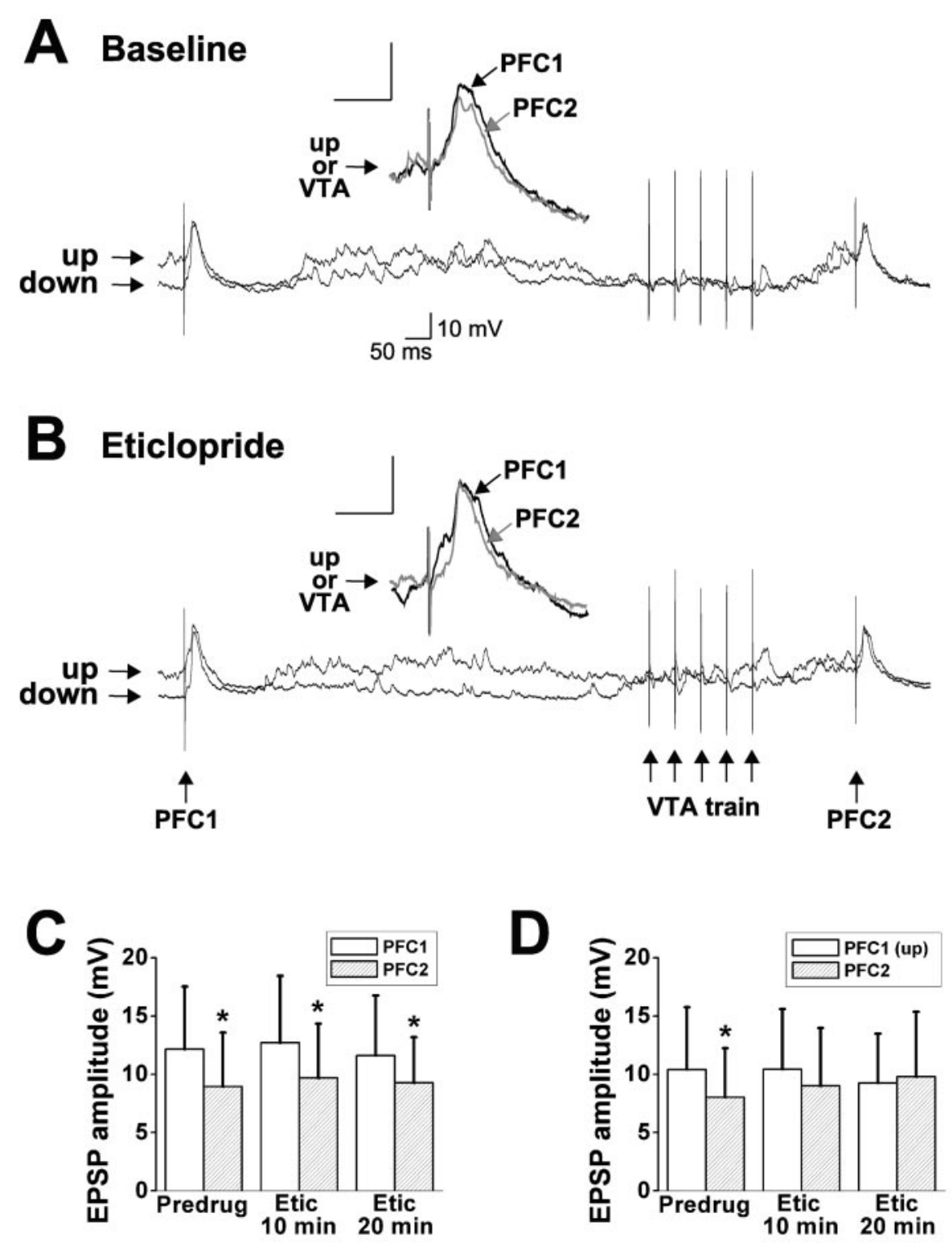

Figure 7. Systemic administration of the $D_{2}$ antagonist eticlopride $(0.5 \mathrm{mg} / \mathrm{kg}$, i.p. $)$ reversed the attenuation of PFC-evoked responses after VTA train stimulation, but only when the comparison was limited to PFC stimulations occurring during spontaneous up states. $A$, Overlay of two traces from one cell, illustrating the baseline (predrug) response to combined PFC (1.0 mA) and VTA train stimulation. Over all of the repetitions, the amplitude of the response to PFC2 in this cell averaged $70.5 \%$ of the response to PFC1. Inset, Detail of the EPSPs as in Figure $6 A$, comparing PFC1 during a spontaneous up state and PFC2 during the VTA-elicited plateau. The EPSP amplitude in response to PFC2 averaged $89.6 \%$ of the PFC1 EPSP amplitude, when PFC1 stimulation occurred during a spontaneous up state. $B, 0$ verlay of two traces from the same cell as in $A$ during the second postdrug time period ( $20 \mathrm{~min}$ after eticlopride injection). After drug administration, the amplitude of the response to PFC2 averaged $81.9 \%$ of the response to PFC1, over all of the repetitions. Inset, Detail of EPSPs as in Figure $6 B$, illustrating that eticlopride blocked the ability of VTA train stimulation to reduce the amplitude of PFC-elicited EPSPs (PFC2 $=122.8 \%$ of PFC1), in comparison with spontaneous up states. Calibration: (in insets) $10 \mathrm{mV}, 30 \mathrm{msec}$. C, Summary of results from all of the cells $(n=7)$, illustrating that PFC response amplitude remained attenuated after VTA stimulation, across all three predrug and postdrug time points, when all of the stimulation repetitions were analyzed. Labeled time points on the abscissa represent a range of times postdrug (10 $\min =9-13 \mathrm{~min} ; 20$ $\min =18-24 \mathrm{~min}$ ). Error bars in ( and D represent SDs from the mean. D, Summary of results from all of the cells illustrating the eticlopride-induced reversal of the attenuation of PFC responses when the analysis was limited to PFC stimulations occurring during up states. ${ }^{*} p<0.04$ [main effect of PFC stimulation ( $C$; ; paired $t$ tests $(D)$ ].

inappropriate selection of limbic and cortical afferents, and may underlie the behavioral and cognitive impairments observed in neuropsychiatric disorders as schizophrenia (O’Donnell and Grace, 1998) and drug addiction (Robinson and Berridge, 1993). 


\section{References}

Berridge KC, Robinson TE (1998) What is the role of dopamine in reward: hedonic impact, reward learning, or incentive salience? Brain Res Brain Res Rev 28:309-369.

Charara A, Grace AA (2003) Dopamine receptor subtypes selectively modulate excitatory afferents from the hippocampus and amygdala to rat nucleus accumbens neurons. Neuropsychopharmacology 28:1412-1421.

Corbit LH, Muir JL, Balleine BW (2001) The role of the nucleus accumbens in instrumental conditioning: evidence of a functional dissociation between accumbens core and shell. J Neurosci 21:3251-3260.

Dalia A, Uretsky NJ, Wallace LJ (1998) Dopaminergic agonists administered into the nucleus accumbens: effects on extracellular glutamate and on locomotor activity. Brain Res 788:111-117.

DeFrance JF, Sikes RW, Chronister RB (1985) Dopamine action in the nucleus accumbens. J Neurophysiol 54:1568-1577.

Finch DM (1996) Neurophysiology of converging synaptic inputs from the rat prefrontal cortex, amygdala, midline thalamus, and hippocampal formation onto single neurons of the caudate/putamen and nucleus accumbens. Hippocampus 6:495-512

Floresco SB, Blaha CD, Yang CR, Phillips AG (2001) Modulation of hippocampal and amygdalar-evoked activity of nucleus accumbens neurons by dopamine: cellular mechanisms of input selection. J Neurosci 21:2851-2860.

French SJ, Totterdell S (2002) Hippocampal and prefrontal cortical inputs monosynaptically converge with individual projection neurons of the nucleus accumbens. J Comp Neurol 446:151-165.

Garris PA, Ciolkowski EL, Pastore P, Wightman RM (1994) Efflux of dopamine from the synaptic cleft in the nucleus accumbens of the rat brain. J Neurosci 14:6084-6093.

Gonon F, Sundstrom L (1996) Excitatory effects of dopamine released by impulse flow in the rat nucleus accumbens in vivo. Neuroscience 75:13-18.

Goto Y, O'Donnell P (2001) Network synchrony in the nucleus accumbens in vivo. J Neurosci 21:4498-4504.

Goto Y, O'Donnell P (2002) Timing-dependent limbic-motor synaptic integration in the nucleus accumbens. Proc Natl Acad Sci USA 99:13189-13193.

Groenewegen HJ, Mulder AB, Beijer AVJ, Wright CI, Lopes da Silva FH, Pennartz CMA (1999) Hippocampal and amygdaloid interactions in the nucleus accumbens. Psychobiology 27:149-164.

Harvey J, Lacey MG (1996) Endogenous and exogenous dopamine depress EPSCs in rat nucleus accumbens in vitro via D1 receptors activation. J Physiol 492:143-154.

Horvitz JC (2000) Mesolimbocortical and nigrostriatal dopamine responses to salient non-reward events. Neuroscience 96:651-656.

Hyman SE, Hyman SE, Malenka RC (2001) Addiction and the brain: the neurobiology of compulsion and its persistence. Nat Rev Neurosci 2:695-703.

Kalivas PW, Duffy P (1995) Selective activation of dopamine transmission in the shell of the nucleus accumbens by stress. Brain Res 675:325-328.

Kiyatkin EA, Rebec GV (1996) Dopaminergic modulation of glutamateinduced excitations of neurons in the neostriatum and nucleus accumbens of awake, unrestrained rats. J Neurophysiol 75:142-153.

Lewis BL, O'Donnell P (2000) Ventral tegmental area afferents to the prefrontal cortex maintain membrane potential "up" states in pyramidal neurons via $\mathrm{D}_{1}$ dopamine receptors. Cereb Cortex 10:1168-1175.

Meredith GE, Totterdell S (1999) Microcircuits in nucleus accumbens' shell and core involved in cognition and reward. Psychobiology 27:165-186.

Mogenson GJ, Yang CR, Yim CY (1988) Influence of dopamine on limbic inputs to the nucleus accumbens. Ann NY Acad Sci 537:86-100.

Mulder AB, Manshanden I, Vos PE, Wolterink G, van Ree JM, Lopes da Silva FH (1996) Modifications in glutamatergic transmission after dopamine depletion of the nucleus accumbens. A combined in vivo/in vitro electrophysiological study in the rat. Neuroscience 72:1009-1021.

Nicola SM, Malenka RC (1997) Dopamine depresses excitatory and inhibitory synaptic transmission by distinct mechanisms in the nucleus accumbens. J Neurosci 17:5697-5710.

Nicola SM, Kombian SB, Malenka RC (1996) Psychostimulants depress excitatory synaptic transmission in the nucleus accumbens via presynaptic $\mathrm{D}_{1}$-like dopamine receptors. J Neurosci 16:1591-1604.
Nicola SM, Surmeier J, Malenka RC (2000) Dopaminergic modulation of neuronal excitability in the striatum and nucleus accumbens. Annu Rev Neurosci 23:185-215.

O'Donnell P (1999) Ensemble coding in the nucleus accumbens. Psychobiology 27:187-197.

O’Donnell P (2003) Dopamine gating of forebrain neural ensembles. Eur J Neurosci 17:429-435.

O’Donnell P, Grace AA (1994) Tonic D2-mediated attenuation of cortical excitation in nucleus accumbens neurons recorded in vitro. Brain Res 634:105-112.

O’Donnell P, Grace AA (1995) Synaptic interactions among excitatory afferents to nucleus accumbens neurons: hippocampal gating of prefrontal cortical input. J Neurosci 15:3622-3639.

O'Donnell P, Grace AA (1996) Dopaminergic reduction of excitability in nucleus accumbens neurons recorded in vitro. Neuropsychopharmacology 15:87-97.

O'Donnell P, Grace AA (1998) Dysfunctions in multiple interrelated systems as the neurobiological bases of schizophrenic symptom clusters. Schizophr Bull 24:267-283.

Pennartz CM, Dolleman-Van der Weel MJ, Kitai ST, Lopes da Silva FH (1992) Presynaptic dopamine D1 receptors attenuate excitatory and inhibitory limbic inputs to the shell region of the rat nucleus accumbens studied in vitro. J Neurophysiol 67:1325-1334.

Pennartz CM, Groenewegen HJ, Lopes da Silva FH (1994) The nucleus accumbens as a complex of functionally distinct neuronal ensembles: an integration of behavioural, electrophysiological and anatomical data. Prog Neurobiol 42:719-761.

Rebec GV, Christensen JR, Guerra C, Bardo MT (1997) Regional and temporal differences in real-time dopamine efflux in the nucleus accumbens during free-choice novelty. Brain Res 776:61-67.

Robinson TE, Berridge KC (1993) The neural basis of drug craving: an incentive-sensitization theory of addiction. Brain Res Brain Res Rev 18:247-291

Salamone JD, Aberman JE, Sokolowski JD, Cousins MS (1999) Nucleus accumbens dopamine and rate of responding: neurochemical and behavioral studies. Psychobiology 27:236-247.

Schultz W (1998) Predictive reward signal of dopamine neurons. J Neurophysiol 80:1-27.

Sesack SR, Pickel VM (1990) In the rat medial nucleus accumbens, hippocampal and catecholaminergic terminals converge on spiny neurons and are in apposition to each other. Brain Res 527:266-279.

Sesack SR, Pickel VM (1992) Prefrontal cortical efferents in the rat synapse on unlabeled neuronal targets of catecholamine terminals in the nucleus accumbens septi and on dopamine neurons in the ventral tegmental area. J Comp Neurol 320:145-160.

Suaud-Chagny MF, Dugast C, Chergui K, Msghina M, Gonon F (1995) Uptake of dopamine released by impulse flow in the rat mesolimbic and striatal systems in vivo. J Neurochem 65:2603-2611.

Swerdlow NR, Geyer MA, Braff DL (2001) Neural circuit regulation of prepulse inhibition of startle in the rat: current knowledge and future challenges. Psychopharmacology (Berl) 156:194-215.

Tarazi FI, Baldessarini RJ (1999) Regional localization of dopamine and ionotropic glutamate receptor subtypes in striatolimbic brain regions. J Neurosci Res 55:401-410.

Uchimura N, Higashi H, Nishi S (1986) Hyperpolarizing and depolarizing actions of dopamine via D-1 and D-2 receptors on nucleus accumbens neurons. Brain Res 375:368-372.

Van Bockstaele EJ, Pickel VM (1995) GABA-containing neurons in the ventral tegmental area project to the nucleus accumbens in rat brain. Brain Res 682:215-221.

White FJ, Wang RY (1986) Electrophysiological evidence for the existence of both D-1 and D-2 dopamine receptors in the rat nucleus accumbens. J Neurosci 6:274-280.

Yang CR, Mogenson GJ (1984) Electrophysiological responses of neurones in the nucleus accumbens to hippocampal stimulation and the attenuation of the excitatory responses by the mesolimbic dopaminergic system. Brain Res 324:69-84.

Yim CY, Mogenson GJ (1988) Neuromodulatory action of dopamine in the nucleus accumbens: an in vivo intracellular study. Neuroscience 26:403415 . 